Ärztliche Erfahrung beschränkt sich nicht auf medizinisches Fachwissen. Sie entsteht auch aus den mehr oder minder alltäglichen, heiter, ärgerlich oder nachdenklich stimmenden Erlebnissen mit Patienten, Kollegen und Mitarbeitern. Senden Sie uns Ihre Geschichte an: Brigitte.Moreano@springer.com. Für jeden veröffentlichten Text erhalten Sie bis zu 100 Euro.

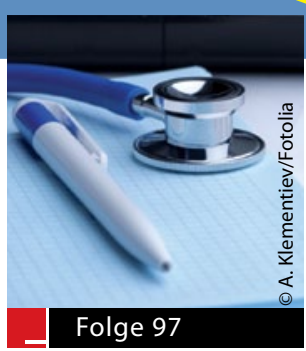

\section{Neueste STIKO- Empfehlung aus Persien}

- Eine iranische Mutter, immer etwas depressiv drauf, hatte um einen Gesprächstermin bei mir gebeten. Sie war in die Schule zitiert worden, zum Elterngespräch. Ihre beiden Töchter, 12 und 13 Jahre alt, seien verhaltensauffällig. Es handelte sich nach meiner Meinung um typische Probleme in der Pubertät, beruhigte ich sie.

Am Ende des Gespräches bat sie mich jedoch um eine "Zickenimpfung" für ihre Töchter. "Nein, dagegen gibt es beileibe wirklich keine Impfung", rief ich aus.

"Doch, doch Frau Doktor", insistierte sie, und deutete auf ein Poster in meinem Wartezimmer. Darauf war eine dicke (elektronenmikroskopisch vergrößerte) Zecke abgebildet.

DR. MED. LUISE HESS, DARMSTADT -

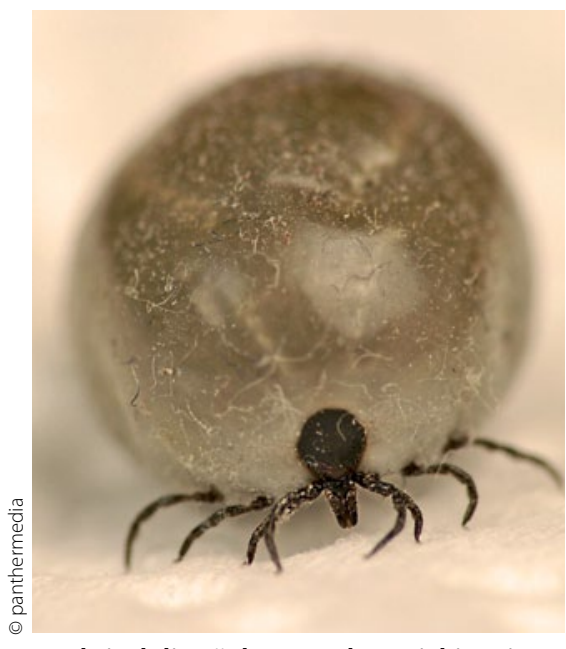

Und sind die Töchter noch so zickig, eine Zeckenimpfung ist doch sinnvoll.

\title{
Problembürger mit herabgesetzter Hemmschwelle
}

_ Ein 53-jähriger Bauarbeiter war 1958 zur stationären Behandlung eines Ulcus duodeni in die Innere Abteilung einer kleinen Ostberliner Spezialklinik aufgenommen worden, nachdem er, obwohl arbeitsunfähig krank geschrieben, seinen Wohnungsnachbarn nachts um zwei Uhr verprügelt hatte. Bei der Visite am nächsten Tag, er lag in einem Sechsbettzimmer, fragte er herausfordernd: „Wo sind denn eigentlich die meisten Ulkusse aufgetreten, beim Kaiser, beim Hitler oder bei den Kommunisten heute?"

Die Stationsschwester, eine Dame mittleren Alters mit dem Abzeichen „Evangelische Frauenhilfe" an der Schwesterntracht, nahm mir die Antwort ab: „Unter- lassen Sie solche unsachlichen Fragen, Sie sind hier schließlich in einem Krankenhaus!"

"Krankenhaus, jawohl, Oberschwester", polterte der Patient, "das erklären Sie 'mal dem Jelben da drüben, das hier is'n Krankenhaus und kein Aufklärungslokal von der Nationalen Front! Da soll Einer jesund werden, wenn man sich den janzen Tag dem sein politisches Gelaber anhören muss!"

Der "Gelbe" war ein hauptberuflicher SED-Funktionär, der zur Abklärung eines Verschlussikterus in der Klinik lag. Nach der Visite hatte die erfahrene Stationsschwester alter Schule einige Mühe, die beiden Kampfhähne nachhaltig zu besänftigen.

DR.MED. ECKART TÖPPICH, ULLERSDORF "

\section{Eine gelungene Narbe}

- Ein Kollege, der ständigen Gängelei durch Standesorganisationen und Regierung müde, war von der Praxis in die Gastronomie gewechselt und bot "Tafelrunden einschließlich Übernachtungsmöglichkeit" an. Zu solch einer Tafelrunde waren wir zusammen mit zwei weiteren Ehepaaren aus der ärztlichen Zunft eingeladen. Das vorzügliche Menü, abgestimmt mit nicht minder hervorragenden Weinen, lockerte unsere Zungen und wir tauschten Episoden aus unserem Berufsleben aus. Naturgemäß erinnert man sich anderntags kaum noch an eine der Geschichten. Eine Anekdote ist jedoch bei mir hängen geblieben.
Nicht nur Klinikärzte und Niedergelassene, sondern auch die Uniform tragenden Kollegen, welche die Ehre des Vaterlandes am Hindukusch verteidigen, sind zur ständigen Fortbildung vergattert. Anlässlich einer solchen Fortbildungsveranstaltung wurde unser wehrdienstgeknechteter Freund von einem Leidensgenossen in Uniform angesprochen, ob die Stabs-ärzte im Lazarett auch in der Lage wären, Operationen wie Abszessspaltungen oder Entfernen von Atheromen durchzuführen, wobei er ihm die rechte Wange zuwandte, auf der ein großes Atherom prangte. Zur Ehrenrettung aller Uniform tragenden Ärzte ant- 